\title{
Is monitoring implementation the key to preventing repeated workplace corruption?
}

Commonwealth Journal of Local Governance

Issue 7: November 2010

http:/lepress.lib.uts.edu.au/ojs/index.php/cjlg

\section{Ray Plibersek}

Sutherland Shire Council

Sydney, Australia

\author{
Alexandria Mills \\ Independent Commission Against Corruption \\ Sydney, Australia
}

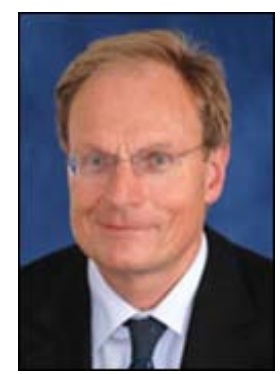

1.

Introduction

Survey results published in 2009 by the Independent Commission Against Corruption (ICAC) of New South Wales ${ }^{1}$ reported that most public sector organisations in its jurisdiction have established integrity policies and procedures - or 'organisational integrity systems' (ICAC 2009). ${ }^{2}$ Despite this, many of the public inquiries conducted by the ICAC that find corrupt conduct often also find a failure to implement or enforce existing anti-corruption mechanisms in agencies. More recently an ICAC inquiry reported that similar patterns of repeated corrupt conduct had been pervasive in one government agency since the early 1990s despite being prohibited by organisational policy (ICAC 2008). These findings are also consistent with the anecdotal experience of integrity practitioners that public sector agencies are experiencing repeated workplace corruption despite the presence of apparently adequate organisational integrity systems. When workplace corruption is exposed, it may be professionally investigated and reforms to address the problems proposed and attempted, yet the same or similar workplace corruption reoccurs. As Barber suggests, ensuring successful delivery requires

\footnotetext{
1 The Independent Commission Against Corruption (ICAC) was created by the ICAC Act 1988. Its aims are to protect the public interest, prevent breaches of public trust and guide the conduct of public officials. The ICAC has the authority to investigate any matter involving public sector corruption in NSW.

2 Organisational integrity systems are policy and operational frameworks that are intended to integrate an organisation's anti-corruption strategies. They usually comprise standard elements including risk assessment, audit and investigation capacity, reporting, education and training, organisational controls and policies, administrative structures, leadership and communication.
} 
a "long grind" of "steady, persistent implementation" and "gentle pressure, relentlessly applied” (Barber2008:112 and 119).

This paper examines cases of low-level non-compliance in a municipal waste collection services and a state owned railway to identify some of the factors that could be contributing to reoccurring workplace corruption. The analysis suggests that a major factor in repeated workplace corruption is the failure to monitor and implement reforms recommended by investigations and existing organisational integrity systems.

\section{Sutherland Shire Council Waste and Cleansing Services}

\section{Investigation ${ }^{3}$}

Sutherland Shire Council is a large metropolitan local (or municipal) government area in southern Sydney, Australia. It has an annual budget of about AUD \$220 million and employs about 1,400 staff. It is responsible for providing services to the local area such as planning/building controls, road construction, environmental management and cleaning/waste collection.

In 2005 the council received a number of complaints about the service provided by its Waste and Cleansing Services for the collection of commercial waste from shops and businesses. These complaints were investigated by the council's Internal Ombudsman. They included:

- Cleansing Services collecting commercial waste from shops, restaurants and businesses that were not paying customers of the council.

- Extra non-contracted waste being collected from council customers above the agreed amounts without extra payment.

- Private bins or waste being collected from private residences.

- Private waste being collected from the homes of council employees.

- Cleansing Services employees using council vehicles to conduct private business such as moving furniture.

- Some Cleansing Services employees receiving small amounts of cash or food and drinks from shops and businesses for collecting extra waste without any payment to the council.

\footnotetext{
3 This case study is based on material first presented in Canberra, Australia, at the Second Annual Ethical Leadership \& Governance in the Public Sector conference. (Plibersek 2008)
} 
Council's Internal Ombudsman investigated the allegations including conducting surveillance of the Waste and Cleansing Services employees. The investigation found many of the allegations outlined above proven. ${ }^{4}$ However, because the activities appeared to be infrequent and the evidence of systemic corruption was inconclusive the investigation was unable to make a finding of entrenched corruption. The investigation also demonstrated that the council's comprehensive Code of Conduct and process/supervisory controls were inadequate in preventing the alleged corrupt conduct. Although corruption controls were generally in place, they were not observed by staff nor enforced by management.

\section{7-2008 Investigation}

In 2007 further complaints were received that extra or unauthorised waste continued to be collected and that Sutherland's waste employees continued to receive gifts/food or payments. These complaints suggested that the activity was more widespread than was first identified in 2005. As a result of these complaints a second investigation was made into the same area. In summary, the 2007-2008 investigation found the existence of the following activities.

- Immediately after the 2005 investigation, the waste employees that were not implicated took it as a green light to continue their corrupt activities. Training in corruption prevention and the Code of Conduct was dismissed by many employees as being theoretical and not applicable to them. For these employees it was 'business as usual'.

- Waste truck drivers having a large organised network of business locations where added waste collection services were being provided for their own personal gain.

- Demands that relief drivers undertake these added waste collections on corrupt employees' behalf when they are off duty to maintain the unauthorised waste collections.

- Evidence that if relief drivers refused to undertake these added unauthorised waste collections pressure was brought to bear on those drivers suggesting that their job depended on it.

- Division of Cleansing Services employees into two factions, one involved in the corrupt behaviour and another which was aware of the behaviour but 'looked the other way’.

\footnotetext{
${ }^{4}$ Internal Ombudsman Sutherland Shire Council “Investigation into Cleansing Services” 2005
} 
- Some corrupt employees were protected from being reported because of friendships outside work.

- Rosters were prepared allocating like minded employees together. This ensured the continuation of the system of unauthorised waste collection and minimised the risk of these collections being reported by employees not involved.

- Employees known to be opposed to unauthorised waste collections being threatened with disciplinary action or allocated to less favourable roles.

The investigations by Sutherland Council in 2005, and by the ICAC into nearby Liverpool City Council (to be discussed below), identified a number of corruption risks in waste collection. However, the 2007 complaints concerning Sutherland's Cleansing Services provided evidence of a further significant effect of low level corruption not previously identified. They demonstrated the contagious effect that low level corruption can have on the integrity and ability of a group to do its work efficiently.

As noted above, the 2007 complaints uncovered two 'factions' of employees. One group of employees participated and maintained the system of unauthorised waste collection. This group favoured its members wherever possible, particularly by altering work rosters. Those outside the group were bullied or ostracised and casual staff were pressured to join the unauthorised waste collection. Any supervisors or employees that were not involved did not report it but tolerated the behaviour. This led to a loss of these supervisors' authority and their ability to effectively direct staff to do Cleansing Services authorised work. It also allowed a damaging public perception to develop amongst some of Council's waste customers that Cleansing Services employees were corrupt and that Council management was unable to control corruption.

The 2007 complaints made it clear that despite the program of education and training, the corrupt behaviour had continued and seemed to worsen. Thus the training and education in corruption prevention and the Code of Conduct together with existing management controls were proven to be ineffective to prevent the reoccurring corrupt behaviour. In fact, unknown to the Internal Ombudsman or senior management, after the corruption prevention training had finished, the waste employees still did not view their own behaviour as corrupt but as a part of doing their job or just good customer service. Because of the relatively low level of gifts/food/money involved and as long as the garbage was collected, the waste employees and their immediate supervisors continued 
to treat this behaviour as acceptable and a minor issue not requiring any remedial action. Other recommendations that had been allocated to the Waste and Cleansing Services managers had not been implemented, nor had any senior manager checked implementation.

With the evidence uncovered by the 2007-2008 investigation that the corrupt behaviour present in 2005 had reoccurred - and possibly worsened, the paramount issue now became: What different initiatives or reforms could prevent continual reoccurrence of these same issues?

\section{Ensuring implementation: 2008-09}

It was clear that the 2005 investigation had failed to identify the full extent of the problems and action taken to address them had been inadequate. In the 2007-2008 investigation the first step was to fully analyse the causes of the corruption problem and why the response in 2005 had been ineffective in preventing ongoing corruption. The causes of corrupt behaviour are complex and the subject of much debate. Despite this complexity, or perhaps because of it, what became clear was that for any response to be effective in reducing corrupt behaviour a range of solutions had to be attempted to address the range of possible causes. ${ }^{5}$

One possible approach was to follow an approach pioneered by the Hong Kong ICAC which saw its role as extending beyond the investigation of specific cases to identifying structural factors that gave rise to corrupt behaviour by evaluating how work should be done, how it is actually done, and how it is controlled by managers. These structural factors include: policy weakness, inadequate instructions, unnecessary procedures, inadequate supervision, excessive discretion, unenforced laws and regulations, and misuse or abuse of position (Doig 1995:159).

Another possible approach was suggested by a study of cases in 35 countries that concluded that a combined package of strategies was most effective in dealing with corruption. These strategies included: political will, new laws, new procedures,

\footnotetext{
${ }^{5}$ Frank Anechiarico 1996 at 18-26 argues that there are layers of anti-corruption controls that have been added until the basic purpose of a regulatory body becomes ancillary to its corruption monitoring and control. New corruption controls do not do not displace old ones but rather they supplement them. Anechiarico argues that corruption controls implemented by law enforcement personnel has become the dominant approach in municipal government. These controls incorporating investigation, prevention and deterrence have become ends rather than the means to more effective governing.
} 
enforcement, public awareness, prevention and accountability (Spector, Johnson \& Dinino 2005). Of particular relevance to the Sutherland Waste and Cleansing Services, the Spector study concluded that the effectiveness of anticorruption programs should not be based on what worked elsewhere under different conditions. It argued against the 'tool kit' approach to reform in which “... good ideas are pulled 'out of the box' and expected to work. Whether they will work at all and how they might interact with each other are very complicated questions" (Spector et al. 2005:228). Drawing on these conclusions, what was needed was a careful analysis of the causes of particular instances of corruption and a targeted practical response to each of those factors that were identified as contributing to the corrupt behaviour.

This approach parallels one proposed by Sparrow for dealing with a range of 'harms' that might include poverty, disease, illegal drug trafficking, natural disasters, workplace accidents or corruption. He also advises against applying the regulator's toolkit recommending instead that the tools used to control a particular harm be dictated by an understanding of its "dynamics and dependencies” (Sparrow 2008: 27). He suggests that regulators responsible for reducing harms should see them as individual problems to be solved - or knots to be undone - rather than simply the absence of their opposite. In the Sutherland Waste Services case, for example, the clearly unethical behaviour of the waste employees could not be adequately addressed simply by re-emphasising their ethical obligations.

A Sparrow analysis of the action taken after the 2005 investigation might be that the agency had relied only on its 'broad prevention program' (or organisational integrity system) that aims to promote the good to be desired (general ethical behaviour) rather than attack the specific harm to be reduced (theft, misuse of resources, secret commissions, bullying etc) (2008:36-37).

While this paper asks whether monitoring implementation of reforms is the critical prevention factor, it must be acknowledged that in the Sutherland case considerable efforts were also made to understand how and why the undesirable behaviour had occurred and become so entrenched. The causes of the recurring corruption uncovered in the 2005 investigation of Waste and Cleansing Services seemed to include: inadequate instructions; inadequate supervision; low risk of detection; discriminatory supervisory 
practices; unchecked discretion; unnecessary procedures; unenforced regulations; and misuse or abuse of position; irregular and irrelevant training.

This analysis of the 2005 investigation also suggested a number of other lessons. First, low level or minor corruption cannot be ignored because of its tendency to corrupt the organisational structure that in turn reduces the organisation's ability to work effectively and achieve its goals. Second, just like a broken window was found to be a marker for an increased likelihood of individual crime, so low level corruption can be a marker for at least the potential for ongoing or more serious corruption to develop (Wilson \& Kelling 2003). In Waste and Cleansing Services, for the system of unauthorised waste collection to continue it needs to recruit and then corrupt other employees to ensure its survival. Third, because the corrupt behaviour continued after training in the Code of Conduct and despite the existence of process/supervisory controls, such measures are by themselves ineffective in reducing corrupt behaviour. More or different measures were clearly needed to deal with the recurring problems.

After analysing the reasons for the failure of the 2005 investigation to uncover all the corrupt activity, the next step was to interview a large number of Waste and Cleansing drivers and supervisory staff about their experience of the corruption issues. The interesting point to emerge was the large number and diversity of complaints that many of the drivers had. These complaints included: unfair rostering, unequal pay rates, unfair pay bonus system, unfair distribution of work, use of casual drivers, inconsistent supervisory practices, inadequate training, inadequate performance reviews, bullying and favouritism.

The investigation team realised that one further reason for the failure of the 2005 investigation was the failure to identify the full extent of the problems and to limit the anti-corruption response to training and reliance on ineffective management controls. What was required was a precise analysis of the full range of problems and grievances of the drivers and a comprehensive response to address all of these issues. This process took some months and resulted in a lengthy investigation report with 55 detailed recommendations for reform. The recommended reforms were allocated to a number of senior managers for implementation. A system of reporting back and monitoring the progress of implementation was put into place to allow senior managers and the Internal Ombudsman to ensure implementation and judge whether the reforms were succeeding. 
The entire process of investigation and implementation monitoring took over two years. Some of the training programs dealing with workplace culture are still continuing.

A summary of the recommendations from the 2007-2008 investigation show the diverse and far reaching nature of the reforms that were recommended and implemented:

- Appoint a senior manager to ensure implementation of the reform recommendations.

- Intensive training and counselling of supervisory staff to change poor management practices to promote a team focussed approach.

- Improved management of staff disputes and inter-personal skills.

- Review of staff rosters, use of casual staff and the system of performance review of staff.

- Review of overall communication mechanisms including regular workplace meetings and improved performance reporting.

- Review of the payment of the productivity bonus, division of runs, more efficient use of staff at the end of their shift, taking meal or rest breaks, driver training, providing assistance to drivers for missed bins.

- Improvements in recruitment, appointment and training of staff to make these fairer and more transparent.

- Stricter driver training and annual licence checking.

- Training and cultural change program to reduce the incidence of bullying and harassment.

- Revised and more detailed reporting to allow better monitoring of the effectiveness of reforms.

- Introduction of a totally revised corruption prevention training system based on regular workplace based meetings delivered by managers specifically designed to be relevant to staff.

This revised ethics training program was designed to deliver training that was relevant and tailored to the identified needs of individual workers. Previously all staff were given similar ethics training based on informing staff about each individual council policy. This was found to be ineffective. The new ethics training program was based on a two level system. The first level gives several sessions of training to all staff on the general principles of ethics and good decision making contained in the council's policies such as its Code of Conduct. Those nine principles are: Integrity, Selflessness, Objectivity, 
Honesty, Accountability, Openness, Respect, Leadership, Economy and Efficiency. The aim of adopting this approach is to ensure that staff have a good understanding of the principles which form the basis of corporate policies on staff conduct and ethics. Its purpose is to allow staff to understand the type of behaviour expected of them and to differentiate proper from improper conduct.

The second level is entitled 'Management Assurance' training. This is a decentralised training program of short (15 minutes) regular training delivered by local managers at the workplace. The local managers are provided with notes, training resources and support, and they provide regular briefings to staff in relation to new policy or other issues directly relevant to those employees at that workplace. This type of targeted training is designed to capture staff attention as it is short, focussed specifically on their needs, and is relevant. As it is delivered regularly it acts as a reminder to staff as to what ethical conduct and decision-making is expected of them. It is intended to overcome past criticism made by some staff that the previous training was too theoretical and not applicable to them in their workplace. This model of regular, short and tailored training is based on proven successful models of workplace occupational health and safety training used in Australia.

\section{Measuring and Evaluating the Reforms}

A review of the reporting and implementation of the reforms disclosed the following results. The great majority of reforms recommended by the 2007-2008 investigation were broad ranging. Rather than exclusively targeting corruption prevention, the reforms were designed to respond to the whole range of problems identified or perceived by the staff. The intention was that by addressing all the entrenched problems, in a holistic way, the entire work process would be improved including reducing corruption.

The reforms have led to a complete revision of the way that the work is done, allocated and supervised. Waste truck drivers see the system of recruitment, rostering, work allocation, bonus payments and supervision as fairer and more structured. The perception of staff has changed to be more trusting and team based. The culture of the whole group has been changed so that corruption, bullying and harassment are clearly seen as unacceptable. Staff morale and skills have improved. After lengthy consultation agreement was reached with the drivers and unions to introduce GPS tracking and data logging devices on waste vehicles for safety and data collection purposes. This has 
resulted in improved efficiency and an ability to pay productivity bonuses based on the work actually recorded as being done. All the reforms have resulted in increases of between $5-10 \%$ in revenue, commercial waste customer numbers and productivity by reduction of lost on-the-job time. There has also been a reduction of about $5 \%$ in operational costs.

The key differentiating factors accounting for the failure of the 2005 investigation and the success of the 2007-2008 investigation seem to be attributable to:

- the detailed analysis and identification of the causes of the corrupt behaviour in that particular work area;

- a comprehensive response to all the problems identified by staff including the issues identified as contributing to corruption; and

- the allocation of responsibility for the implementation of reforms to senior managers with a system of close monitoring and evaluation of effectiveness of the implementation.

Addressing each of these factors requires attention to 'little' things that individually might seem insignificant but together contribute to a situation that is exposed to corruption risks.

\section{Related ICAC Inquiries}

Over the last 20 years failure to implement or monitor implementation of reforms has frequently been a factor in public inquiries reported by the NSW Independent Commission Against Corruption. Indeed, a study of the ICAC's first 100 public inquiries found that this had been a factor in $40 \%$ of cases (Cooper \& Mills 2007).

Similar problems to those uncovered in the 2005 investigation into Sutherland's Waste and Cleansing Services have also been found to occur in other waste collection operations. ${ }^{6}$ An example is Liverpool City Council, which is a large local government area in the western suburbs of Sydney. An ICAC investigation of Liverpool City Council's privately contracted waste services found that financial losses occurred because vehicles that should have been used for domestic waste collection were collecting commercial waste and charging the disposal fees to Liverpool Council (ICAC

${ }^{6}$ The ICAC has conducted investigations and issued discussion papers addressing problems of corruption in local government cleansing and waste services. See ICAC Discussion Paper Taking the Whiff out of Waste. 
2001). There were no checks on what the vehicles were collecting or on what charges were being incurred. Nor were there checks on waste disposal fees to reconcile these with the amount of waste being collected. The ICAC determined that Liverpool City Council had poor systems, inadequate monitoring and inexperienced staff. It lost significant amounts of revenue. The ICAC report concluded that risks for Councils in relation to waste collection and transportation generally include:

- loss of revenue from fraudulent or negligent performance;

- loss of reputation from poor service delivery;

- damage to commercial and community credibility through inadequate monitoring;

- damage to the environment from wilful or negligent waste disposal; and

- damage to the recycling of waste policy from failure to properly differentiate waste products resulting in disposal of recyclable material.

ICAC (2002) subsequently produced a discussion paper Taking the Whiff out of Waste that noted common allegations of corruption in the waste industry include:

- misuse or theft of waste resources;

- links between the waste industry and organised crime;

- failure to make or keep proper records;

- fraudulently altering waste weight records; and

- bribery and collusion between interested parties.

There is substantial money to be made operating outside the regulated industry, and the threat of detection is seen to be particularly low. ICAC concluded that government agencies are at risk of losing valuable resources through theft and misappropriation of valuable recyclable waste assets, as well as the loss of income from the fees they derive in providing waste services. Furthermore, it could also fall to the agency or council to contribute to the cost of remedying any environmental damage caused by illegal dumping.

The ICAC has also investigated repeated allegations of bribery, corruption and fraud at RailCorp (a state owned railway corporation). It has conducted eight inquiries over 16 years involving this agency in its various incarnations (ICAC 1992; ICAC 1993; ICAC 1998; ICAC 2001; ICAC 2006; ICAC 2007; ICAC 2008a; ICAC 2008b). These investigations reported findings of corrupt conduct on the part of 31 individuals 
including 14 RailCorp employees and staff of 16 private firms. The investigations exposed 'endemic and enduring' (ICAC 2008b:11) corruption involving employees and managers at many levels of the organisation. They uncovered fraud, bribery, improper allocation of contracts, unauthorised secondary employment, failure to declare conflicts of interest, false time sheets, and the cover-up of a safety breach. RailCorp employees were found to have improperly allocated contracts totalling almost \$19 million to companies owned by themselves, their friends or their families, in return for corrupt payments totalling over $\$ 2.5$ million (ICAC 2008b:5). Over 400 suggested criminal charges were referred for possible prosecution (ICAC 2008b:12).

The ICAC investigation found that the structure of RailCorp and the way it operated allowed and encouraged corruption. Contracting and purchasing procedures, reporting processes and poor management controls were all found to contribute to endemic corruption. The ICAC concluded that:

...the decision to outsource the provision of certain goods and services in an
environment of dysfunctional markets, a lack of internal firewalls within
procurement positions, the inability of management to effectively manage the
procurement process, and the weak oversight by the RailCorp Board of an activity
fraught with corruption risks, worked in concert to allow the widespread
corruption to develop (ICAC 2008b:11).

The investigations exposed widespread corruption in many levels of RailCorp from workers to senior managers. Corrupt employees seemed confident that they would not be caught. The ICAC inquiry heard intercepted telephone evidence of conversations between RailCorp employees showing that corrupt purchasing practice were continuing at the same time as evidence about the same type of corrupt conduct by other RailCorp employees was being heard by the inquiry and reported in the media.

The investigations revealed serious and widespread management failures in the Asset Management Group (AMG) within RailCorp. These failures worsened the problems associated with the procurement process and assisted the continuation of corrupt conduct. Managers within the AMG failed to properly check the work of their staff, failed to take action to manage known corruption risks, and failed to ensure proper recordkeeping or to conduct proper checks. As a result, the ICAC inquiry found there was no credible threat of detection to act as a deterrent to prevent corrupt conduct (ICAC 2008b: 5). ${ }^{7}$

\footnotetext{
${ }^{7}$ Because of the size and seriousness of these management failures the ICAC made a number of recommendations to reduce the corruption uncovered by the investigation. These include the appointment of an external expert to develop and implement change in the AMG, a review of the responsibilities of
} 
The ICAC reported preventing corruption in RailCorp was not a priority for the senior executive managers. It noted that whilst Railcorp had an Internal Audit unit which had identified problems including corruption, senior management had failed to implement its recommendations (ICAC 2008b: 56). In December 2006 the RailCorp Board commissioned Deloitte Touche Tohmatsu to undertake an independent review of issues brought to its attention relating to three individuals. The Deloitte report found that:
... many of the procurement and contract management issues raised in this report were investigated and referred to the ICAC by RailCorp's investigations and internal audit. We note however that had the recommendations made by the [Internal Audit] unit in several investigation and internal audit reports been effectively implemented, the need for further investigation and referral to ICAC may have been avoided (ICAC 2008b:56).

The Deloitte report went on to state that:

It appears that many of [Internal Audit's] recommendations have not been adopted or are still in progress, despite the ongoing efforts of Internal Audit to persuade management of the importance and necessity of change (ICAC 2008b:56).

Thus the key lesson from both the eight ICAC RailCorp investigation reports and that of the independent Deloitte audit report, is that the explanation for the failure to prevent reoccurring corruption was the failure to implement identified recommendations. Had the recommendations been effectively implemented, the need for further investigations and repeated anti-corruption work may not have been necessary. This conclusion is similar to that reached in the Sutherland Waste and Cleansing Services case.

\section{Conclusion}

In the light of these cases we answer the question posed in the title of this paper with three observations:

- the causes of repeated corrupt behaviour or problems in a workplace need to be analysed in a specific, rather than generalised, way in their own context;

- the proposed solutions need to target all the relevant behaviours occurring in that context; and finally,

- the successful delivery of reforms aimed at reducing repeated workplace corruption, can be best assured by steady and persistent monitoring and

managers in AMG and a continuous program of management training to improve management skills. The investigation made recommendations to improve significant gaps and deficiencies in RailCorp policies and procedures. These recommendations included: limiting secondary employment of RailCorp staff, a prohibition on the receipt by procurement staff of gifts and benefits from contractors and tenderers, and procedures to ensure that staff, contractors and subcontractors comply with RailCorp's Statement of Business Ethics 
implementation of the reforms recommended after careful investigation of the causes of corruption in that particular workplace.

Further analysis is needed to understand why implementation of recommended reforms is ignored or, more often, abandoned. It may be that public organisations lack the necessary resources or skills. Possibly the contagious effect of low-level non-compliance is underappreciated or the limited capacity of supervisors to influence the behaviour of their staff is not acknowledged.

There are also some fundamental questions to be answered about what kind of activity we are engaging in when we try to reduce the reoccurrence of workplace corruption. Should we look to research and analysis of prevention activities, such as workplace accidents? Alternatively, is it about encouraging compliance with rules which opens up an even wider body of comparable research? Does it require an understanding of the psychology of how we learn and apply ethical principles or virtue ethics? Or is it an even wider issue to do with ensuring the effectiveness of reforms or workplace change, in which case the organisational change and policy implementation literature would be helpful. Perhaps all of these are relevant and useful and should be applied in a combination that can be determined only by understanding the dynamics of the context in which the problem occurs.

\section{References}

Anechiarico, F \&James B Jacobs 1996 The Pursuit of Absolute Integrity: How Corruption Control Makes Government Ineffective, University of Chicago Press, Chicago.

Barber, M 2008, Instruction to Deliver, Fighting to Transform Britain's Public Services, Methuen, London).

Cooper D and Mills A 2007 'Learning from Experience: A project to maintain knowledge-based prevention policy', CIES e-working paper $N^{\circ} 29 / 2007$



Doig A 1995 'Good Government and Sustainable Anti-Corruption Strategies: A Role for Independent Anti-Corruption Agencies? Public Administration and Development 15,2: 151-165.

ICAC 1992 Report on investigation into the State Rail Authority - Trackfast Division Sydney.

ICAC 1993 Report on Investigation into the State Rail Authority - Northern Region Sydney.

ICAC 1998 Report into major investigation into corruption in the former State Rail Authority of NSW Sydney.

ICAC 2001a Investigation into Liverpool City Council, Garbage, Drains and other things (An examination of conduct of two Liverpool City Council Contractors) Sydney.

ICAC 2001b Corrupt networks: report into the conduct of a technical specialist in the State Rail Authority Sydney. 
ICAC 2002 Taking the Whiff out of Waste Discussion Paper Sydney.

ICAC 2006 Report on investigation into defrauding the RTA and RailCorp in relation to provision of traffic management services Sydney.

ICAC 2007 Report on investigation into corrupt conduct associated with RailCorp airconditioning contracts, Sydney.

ICAC 2008a Investigation into bribery and fraud at RailCorp - Seventh Report Sydney.

ICAC 2008b Investigation into bribery and fraud at RailCorp - Eighth Report: Corruption prevention Sydney.

ICAC 2009 Profiling the NSW public sector II - Report: Results for the NSW public sector as a whole Sydney.

Internal Ombudsman Sutherland Shire Council, "Investigation into Cleansing Services” 2005,unpublished.

Plibersek, R 2008 'Ensuring Good Governance in Local Government - The Triple Governance Track.'. Presented at the Second Annual Ethical Leadership \& Governance in the Public Sector Conference, Canberra, June 2008 (unpublished).

Sparrow, M 2008 The Character of Harms, Cambridge University Press, Cambridge.

Spector, B, Johnston, M, Dinino, P 2005 'Learning Across Cases: Trends in Anticorruption Strategies',in Fighting Corruption in Developing Countries Kumarian pp 213-232.

Wilson, J Q and Kelling, G L 2003 "Broken windows: The police and neighbourhood safety” in - Criminological Perspectives: Essential Readings SAGE Publications pp 400-412. 